Article

\title{
Aging of $\gamma^{\prime}$ Precipitates at $750{ }^{\circ} \mathrm{C}$ in the Nickel-Based Superalloy AD730 ${ }^{\mathrm{TM}}$ : A Thermally or Thermo-Mechanically Controlled Process?
}

\author{
Nicolas Mrozowski ${ }^{1,2, *}$, Gilbert Hénaff ${ }^{1, *} \mathbb{0}$, Florence Hamon ${ }^{1}$, Anne-Laure Rouffié ${ }^{2}$, \\ Jean-Michel Franchet ${ }^{2}$, Jonathan Cormier ${ }^{1}$ and Patrick Villechaise ${ }^{1}$ \\ 1 Pprime Institute, UPR CNRS 3346 CNRS-ENSMA, University of Poitiers, ISAE-ENSMA - Teleéport 2, \\ 1st Clément Ader Avenue, BP 40109, 86961 Futuroscope Chasseneuil CEDEX, France; \\ florence.hamon@ensma.fr (F.H.); jonathan.cormier@ensma.fr (J.C.); patrick.villechaise@ensma.fr (P.V.) \\ 2 SAFRAN TECH, Jeunes Bois Street, Châteaufort, CS 80112, 78772 Magny les Hameaux, France; \\ anne-laure.rouffie@safrangroup.com (A.-L.R.); jean-michel.franchet@safrangroup.com (J.-M.F.) \\ * Correspondence: nicolas.mrozowski@ensma.fr (N.M); gilbert.henaff@ensma.fr (G.H.); \\ Tel.: +33-(0)549498233 (N.M.)
}

Received: 17 February 2020; Accepted: 24 March 2020; Published: 25 March 2020

\begin{abstract}
The microstructural stability during aging at $750{ }^{\circ} \mathrm{C}$ of the $\gamma / \gamma^{\prime}$ nickel-based superalloy $\mathrm{AD} 730^{\mathrm{TM}}$ is investigated in this work. Strain-free aging and aging during fatigue tests are conducted, with a focus on the influence of the strain ratio, the maximum applied strain, and the cycle waveform (with or without dwell). Two classical mechanisms of $\gamma^{\prime}$ precipitates aging are identified at $750{ }^{\circ} \mathrm{C}$ : the coarsening of small spherical $\gamma^{\prime}$ precipitates via the thermally-activated Ostwald ripening process and the coalescence of at least two precipitates into one. These mechanisms appeared to be concomitant during aging. It has been demonstrated that the coarsening kinetics of $\gamma^{\prime}$ precipitates can be described by a classical Lifshitz-Slyozow-Wagner (LSW) equation. The introduction of a cyclic strain during aging at $750{ }^{\circ} \mathrm{C}$ increases the coarsening kinetics by means of changes in the volume diffusion of $\gamma^{\prime}$-forming elements and of constraint misfit effects. More precisely, it is shown that the higher the maximum applied strain and/or the strain rate, the higher the coarsening rates. Finally, dwell-fatigue promotes the activation of the $\gamma^{\prime}$ coalescence at $750{ }^{\circ} \mathrm{C}$.
\end{abstract}

Keywords: nickel-based superalloys; growth mechanisms; coarsening; coalescence; fatigue; creep-fatigue; $\gamma^{\prime}$ precipitates; high temperature

\section{Introduction}

Polycrystalline forged $\gamma / \gamma^{\prime}$ nickel-based superalloys are widely used in rotating parts of aero-engines since they retain high mechanical properties at temperatures above $600{ }^{\circ} \mathrm{C}$, thanks to the strengthening $\gamma^{\prime}$ phase and in conjunction with a good oxidation resistance [1,2]. The current need to limit the environmental footprint of aero-engines partly involves an increase in operating temperatures [3]. It is therefore necessary to study the stability of the nickel-based superalloy microstructure when maintained at high temperatures for long durations.

In $\gamma / \gamma^{\prime}$ nickel-based superalloys such as the cast and wrought $\mathrm{AD} 730^{\mathrm{TM}}$ material used in this study [4], the $\gamma^{\prime}$ precipitates $\mathrm{Ni}_{3}(\mathrm{Al}, \mathrm{Ti})\left(\mathrm{L} 1_{2}\right.$ lattice) are coherent with the $\gamma$ matrix (fcc) [5]. Depending on the heat treatment routines and the cooling rates, multimodal $\gamma^{\prime}$ populations with different sizes, morphologies, and chemical compositions can be obtained [1,6-9]. When exposed at high temperatures, the non-equilibrium microstructure may evolve (the so-called over-aging simply referred to as "aging" for the rest of the manuscript), depending on the temperature, chemistry of the alloy, and possible residual (micro-) segregation. One of the evidences of the aging is the increase in the average size of the 
dispersed $\gamma^{\prime}$ phase over time through elemental volume diffusion in the matrix [10]. The growth of $\gamma^{\prime}$ precipitates is of paramount importance since it is well known it can have an impact on the mechanical properties at moderate temperatures $\left(600-800^{\circ} \mathrm{C}\right)$, for example, by decreasing the tensile strength and creep properties [11] or increasing the stress relaxation rates [11,12]. The driving force for this phenomenon is the reduction of the $\gamma / \gamma^{\prime}$ system energy via the decrease of the total interfacial area of dispersed $\gamma^{\prime}$ phase [13]. Two main mechanisms generally arise to enable this total energy decrease: the coarsening via an Ostwald ripening process and the coalescence. For the former, particles with a radius $R$ above a critical radius $R^{*}$ will grow at the expense of those with a radius such as $R<R^{*}$ and eventually end up by being dissolved $[14,15]$. The Ostwald ripening is a thermally-activated phenomenon that has been extensively studied during the past century [10,14,16-22]. In 1961, Lifshitz, Slyozow, and Wagner established an empirical equation relating the average radius $<R>$ of a second phase population to the aging time $t:\langle R\rangle^{3}-\left\langle R_{0}>^{3}=k \times t[23,24]\right.$, where $\left\langle R_{0}>\right.$ is the initial average particle radius, $k$ is the coarsening rate depending, among other parameters, on the $\gamma / \gamma^{\prime}$ surface energy, the aging temperature, and the misfit between the $\gamma$ and $\gamma^{\prime}$ phases [17]. This relation is since then referred as the LSW law and relies on several assumptions such as a second phase volume fraction approaching zero in a stress-free system and negligible interactions between the spherical particles [17]. Although this equation was originally established for simple binary systems, several authors have reported that the growth of $\gamma^{\prime}$ precipitates at high temperatures in nickel-based superalloys can be described by LSW equations and obeys to the Ostwald ripening theory [8,18,25-28]. If the second phase particles are close enough, another solid particle growth mechanism can take place at high temperature, namely the coalescence of two small particles into one coarser particle [29-31]. This phenomenon involves a necking between the two particles ensured by the overlapping of their interdiffusional zones [30-32]. It can be enhanced by a high dislocation density at the $\gamma / \gamma^{\prime}$ interface [33]. Because of the induced merging of two particles into one, the coalescence of particles leads to a decrease in particle density with aging time [31]. Both the coarsening and coalescence mechanisms are involved in the increase in average size of a $\gamma^{\prime}$ precipitates population during aging at high temperature.

The present study is not only focused on the discussion of the stress/strain-free aging of the $\gamma^{\prime}$ precipitates, but aims as well at improving the understanding of aging kinetics when external stresses/strains are applied. Indeed such conditions are considered to be more representative of actual loading conditions and aging taking place at the tip of a fatigue crack. Even though the $\gamma$ and $\gamma^{\prime}$ phases are coherent, their respective lattice parameters are not equal and consequently, a misfit exists between the two phases [34]. This misfit is at the core of the strengthening effect due to the $\gamma^{\prime}$ precipitation and it induces an elastically-accommodated stress field surrounding the precipitates [35]. When an external stress/strain is applied, the misfit [36,37] and the local diffusion potential at the precipitate interfaces [38-40] can change. Both contributions have an impact on the LSW kinetics coefficient and therefore on the growth of $\gamma^{\prime}$ precipitates at high temperature. Moreover, if dislocation glide is activated, dislocations can act as preferential diffusion path for the elements via pipe diffusion, enhancing the $\gamma^{\prime}$ coarsening [35,39,41-44]. The influence of a monotonic loading on the oriented coarsening and/or coalescence of precipitates has been very well documented during this past decade, for instance in an $\mathrm{Al}-\mathrm{Cu}-\mathrm{Mg}-\mathrm{Ag}$ and an Al-Cu alloys by Skrotzki et al.; in Fe-N alloys by Sauthoff $[35,45,46]$; and in nickel-based superalloys [47-54]. This last point mostly consists of numerous works on the very high temperature $\gamma^{\prime}$ rafting in Ni-based single-crystal superalloys, which is a mechanism depending on the $\gamma / \gamma^{\prime}$ misfit sign and amplitude, as well as on the sign of the externally applied stress. Therefore, it is also related to the stress triaxiality, as shown by Caccuri et al. [49] and Cao et al. [55] on single crystal superalloys CMSX-4 and ERBO1 (a variant of CMSX-4 alloy), respectively. However, studies on polycrystalline superalloys [56-58] or on the effect of a cyclic loading on the aging kinetics $[59,60]$ at medium temperature are rather sparse. For that reason, the objective of the present study is to improve the understanding of $\gamma^{\prime}$ coarsening kinetics under a cyclic loading at $750{ }^{\circ} \mathrm{C}$ in the nickel-based superalloy AD730 ${ }^{\mathrm{TM}}$. 


\section{Material and Methods}

\subsection{Material}

The chemical composition of the investigated material $\mathrm{AD} 730^{\mathrm{TM}}$ is given in Table 1.

Table 1. Nominal chemical composition of $\mathrm{AD} 730^{\mathrm{TM}}$ (in weight pct.) [4].

\begin{tabular}{cccccccccccc}
\hline Element & Ni & Cr & Mo & W & Al & Co & Ti & Nb & Fe & C & B \\
\hline Wt. $\%$ & Balance & 16.0 & 3.0 & 2.7 & 2.3 & 8.5 & 3.5 & 1.1 & 4.0 & $<0.02$ & 0.01 \\
\hline
\end{tabular}

A four step heat-treatment, based on the work on the AD730 ${ }^{\mathrm{TM}}$ of Thébaud et al. [3], is applied to the as-received material, a radially forged bar using a GFM -general forging machine- process. The resulting microstructure features are shown in Figure 1.

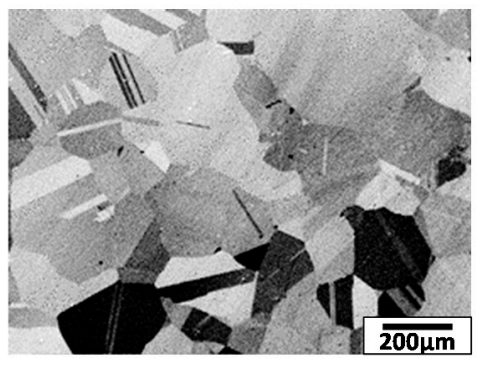

(a)

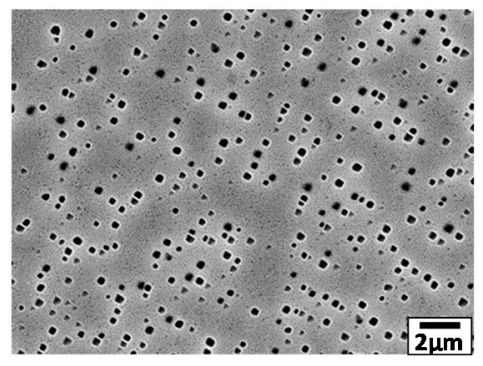

(b)

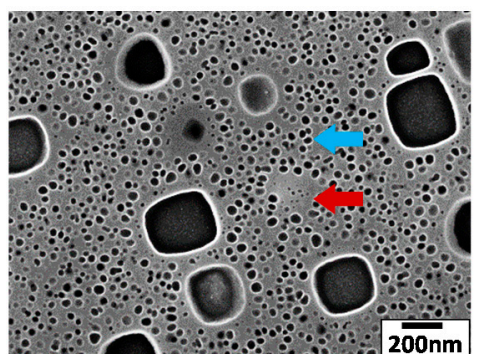

(c)

Figure 1. $\mathrm{AD} 730^{\mathrm{TM}}$ microstructure after the heat-treatment routine applied: (a) Coarse-grained microstructure (SEM, BSE); (b) $\gamma^{\prime}$ precipitation: cubical $\gamma^{\prime}$ precipitates (SEM-FEG, SE); (c) $\gamma^{\prime}$ precipitation: cubical $\gamma^{\prime}$ precipitates, spherical secondary (blue arrow) and tertiary (red arrow) $\gamma^{\prime}$ precipitates (FEG-SEM, SE).

The first heat-treatment step is a supersolvus solution heat-treatment at $1120{ }^{\circ} \mathrm{C}$ for $2 \mathrm{~h}$, so that all the $\gamma^{\prime}$ precipitates previously formed during the cast and wrought processing route are dissolved. A coarse-grained microstructure is obtained as shown Figure 1a, with the average grain size being equal to $210 \pm 10 \mu \mathrm{m}[50-500 \mu \mathrm{m}]$. The subsequent cooling at $\sim 40-60{ }^{\circ} \mathrm{C} / \mathrm{min}$ enables the precipitation of a first $\gamma^{\prime}$ precipitate population. Then, a subsolvus solution heat treatment is performed at 1080 ${ }^{\circ} \mathrm{C}$ for $4 \mathrm{~h}$ to homogenize the microstructure chemistry and to favor a cuboidal shape of undissolved $\gamma^{\prime}$ at this temperature. The following cooling is an air quenching resulting in the precipitation of the second $\gamma^{\prime}$ population. The last two steps are annealing treatments performed at $800{ }^{\circ} \mathrm{C}$ for $4 \mathrm{~h}$ and $760{ }^{\circ} \mathrm{C}$ for $16 \mathrm{~h}$, allowing the precipitation of a third $\gamma^{\prime}$ population and the growth of all the $\gamma^{\prime}$ precipitates. The resulting $\gamma^{\prime}$-precipitation distribution is a trimodal population, as shown in Figure 1c. The population of coarser $\gamma^{\prime}$ precipitates is shown in Figure $1 \mathrm{~b}$ and is cubical in shape. As observed in Figure 1c, the two smallest populations are spherical. It is chosen to label the larger spherical $\gamma^{\prime}$ population as secondary $\gamma^{\prime}\left(\gamma_{\text {II }}^{\prime}\right)$ and the smallest $\gamma^{\prime}$ precipitates as tertiary $\gamma^{\prime}\left(\gamma_{\text {III }}^{\prime}\right)$. The latest population can be mostly found around the cubical $\gamma^{\prime}$ where the supersaturation in $\gamma^{\prime}$-forming elements such as $\mathrm{Al}$ and $\mathrm{Ti}$ is the highest after the secondary $\gamma^{\prime}$ precipitation. Ultimately, it should be noted that the coalescence of precipitates occurrs during the heat treatment.

For the $\gamma^{\prime}$ stereological analysis, each sample is polished up to the $1 \mu \mathrm{m}$ grade with SiC papers. An electropolishing is performed with A3 solution (methanol, butoxyethanol, perchloric acid) from Struers (Struers S.A.S, Champigny, France) at $6-8{ }^{\circ} \mathrm{C}$, for $8 \mathrm{~s}$ and under $45 \mathrm{~V}$. The samples are eventually chemically etched with an aqua regia solution. This last step leads to selective etching of the $\gamma^{\prime}$ phase. The $\gamma^{\prime}$ microstructure images are obtained with a Field Emission Gun JEOL 7000F Scanning Electron Microscope (FEG-SEM, JEOL, Ltd., Akishima, Tokyo, Japan. Observations are conducted 
with a secondary electron detector at a constant acceleration voltage of $25 \mathrm{kV}$ and a $\sim 6 \mathrm{~mm}$ working distance. The smallest $\gamma^{\prime}$ populations are analyzed using 15 images taken in randomly selected zones with a 50,000× magnification. The corresponding area covers $60 \mu \mathrm{m}^{2}$ and at least 5,000 particles per sample are analyzed in order to ensure a sufficient statistics. The Visilog ${ }^{\circledR} 6.9$ software (Thermo Fisher Scientific, Waltham, MA, USA) is used for the subsequent image analysis. The particle characteristics studied are the mean equivalent radius, the surface fraction and density, and the inter-particle distance. Thanks to Visilog®6.9, we count particles and measure their projected surface. The equivalent radius of a particle is the radius of a same projected surface disk. The surface fraction is the percentage of the particles' surface relative to the overall surface analyzed. The surface density is the number of particles counted in $1 \mu \mathrm{m}^{2}$. The spherical $\gamma^{\prime}$ population characteristics obtained just after the heat treatment, which will be referred as the initial $\gamma^{\prime}$ precipitation state from now on, are presented in Table 2. An overlap of the two spherical populations exists on the particle size distribution (PSD) functions. A last step of peak deconvolution with two Gaussians is required to describe the particle sizes. In this study, the means of the two fitted Gaussians are used as the mean particle size for each $\gamma^{\prime}$ population. The mean characteristics of the two spherical $\gamma^{\prime}$ population combined (i.e., $\gamma_{\text {II }}^{\prime}+\gamma_{\text {III }}^{\prime}$ ) are also studied. It should be noted that particles with a size smaller than $10 \mathrm{~nm}$ are not analyzed due to the SEM resolution limit and image artefacts.

Table 2. Initial particle characteristics of $\gamma^{\prime}$ precipitates at aging $\mathrm{t}=0 \mathrm{~h}$.

\begin{tabular}{ccccc}
\hline Particle Populations & $\begin{array}{c}\text { Equivalent } \\
\text { Diameter }(\mathbf{n m})\end{array}$ & $\begin{array}{c}\text { Surface Fraction } \\
(\mathbf{\%})\end{array}$ & $\begin{array}{c}\text { Surface Density } \\
\left(\boldsymbol{\mu \mathbf { m } ^ { - 2 } )}\right.\end{array}$ & $\begin{array}{c}\gamma \text { Width } \\
(\mathbf{n m})\end{array}$ \\
\hline Cubical $\gamma^{\prime}$ & $293 \pm 15$ & $10.1 \pm 0.5$ & $1.40 \pm 0.1$ & - \\
Spherical secondary $\gamma^{\prime}$ & $28.7 \pm 2.3$ & $14.3 \pm 1.0$ & $179.0 \pm 12$ & $34.3 \pm 1.5$ \\
Spherical tertiary $\gamma^{\prime}$ & $14.7 \pm 1.5$ & $0.40 \pm 0.05$ & $30.0 \pm 4.0$ & - \\
Coalescing & $35.3 \pm 2.8$ & $1.58 \pm 0.3$ & $15.7 \pm 3.0$ & - \\
\hline
\end{tabular}

As previously said, some $\gamma^{\prime}$ precipitates coalesce during the heat treatment, introducing a fourth $\gamma^{\prime}$ population of coalescing particles (i.e., particles whose necking phase is still noticeable). During the image analysis, these particles are discriminated from the others by considering their aspect ratio $A_{R}$, with $A_{R}=\frac{d_{\max }}{d_{\min }}, d_{\text {min }}$, and $d_{\max }$ being the minimal and maximal orthogonal diameters. The aspect ratio of coalescing particles is greater than 1.2, while the non-coalescing spherical particles have an aspect ratio between 1 and 1.2. The characteristics of the coalescing particles in the initial microstructure can be found in Table 2.

Cylindrical specimens of $\sim 13 \mathrm{~mm}$ in diameter and $\sim 4 \mathrm{~mm}$ in height are used for the study of the strain-free aging of the $\mathrm{AD} 730^{\mathrm{TM}}$ microstructure at $750{ }^{\circ} \mathrm{C}$. The samples are exposed in a resistive furnace up to $429 \mathrm{~h}$ (temperature accuracy of $+/-1^{\circ} \mathrm{C}$ ).

Tensile tests are conducted on the heat-treated specimens to determine initial mechanical characteristics of the material. At $750{ }^{\circ} \mathrm{C}$ and with a strain rate of $5.0 \times 10^{-4} \cdot \mathrm{s}^{-1}$, the Young modulus $E$ is $164 \mathrm{GPa}$, the yield strength $R_{p 0.2 \%}$ is around $880 \mathrm{MPa}$, and the ultimate tensile test $R_{m}$ is around $1030 \mathrm{MPa}$.

\subsection{Interrupted Strain-Controlled Fatigue Tests}

Cylindrical blanks are heat-treated following the procedure previously described. Cylindrical fatigue specimens are then machined from these blanks. The total length of the specimen is $56 \mathrm{~mm}$ and the heads' diameter is $12 \mathrm{~mm}$. The gauge length is $13 \mathrm{~mm}$ long and the diameter is $4.3 \mathrm{~mm}$. Prior to testing, the gauge lengths are low-stress mirror-polished up to the $1 \mu \mathrm{m}$ diamond paste grade. The strain-controlled fatigue test matrix is presented in Table 3. All tests are performed at $750{ }^{\circ} \mathrm{C}$ in laboratory air and with an Instron 8862 machine (Instron, Norwood, MA, USA). Two loading waveforms are used: 10-0-10 pure fatigue cycles with $10 \mathrm{~s}$ loading and unloading $(f=0.05 \mathrm{~Hz})$ and 10-300-10 dwell-fatigue cycles with a dwell-period at maximum strain of 300 s. Two strain ratios 
are considered: $R_{\varepsilon}=-1$ and $R_{\varepsilon}=0.05$. Tests at $R_{\varepsilon}=-1$ are performed with two total strain ranges of $\Delta \varepsilon_{t}=0.6 \%$ and $\Delta \varepsilon_{t}=0.4 \%$. These ranges are chosen so that the test durations provide proper conditions for the analysis of aging effects. In order to compare the results, tests at $R_{\varepsilon}=0.05$ are performed by considering the same values of the maximal strain, namely $0.3 \%$ and $0.2 \%$. Since the waveforms remain unchanged regarding the total strain ranges applied, one can note that the strain rates vary from one test to another. All the fatigue tests are interrupted at $186 \mathrm{~h}$ so as to compare the different aged microstructures. This duration is chosen based on the duration of the shortest test (the only one leading to rupture). All the other tests are longer and therefore are interrupted tests. As indicated in Table 3, additional test durations are included for the test condition "pure fatigue $-R_{\varepsilon}$ $=-1-\Delta \varepsilon_{t}=0.4 \%$ " in order to investigate the effect of cyclic straining on the aging kinetics.

Table 3. Interrupted strain-controlled test matrix at $750{ }^{\circ} \mathrm{C}$.

\begin{tabular}{cccccc}
\hline Test & $\boldsymbol{R}_{\boldsymbol{\varepsilon}}$ & $\boldsymbol{\varepsilon}_{\max }$ & $\boldsymbol{\Delta} \boldsymbol{\varepsilon}$ & Strain Waveform & Duration \\
\hline $\begin{array}{c}\text { Fatigue } \\
\text { Fatigue* }\end{array}$ & -1 & $0.2 \%$ & $0.4 \%$ & $10-0-10$ & $186 \mathrm{~h}$ \\
*Only test carried out & -1 & $0.3 \%$ & $0.6 \%$ & $10-0-10$ & $186 \mathrm{~h}$ \\
up to failure & & & & & \\
Fatigue Dwell & -1 & $0.2 \%$ & $0.4 \%$ & $10-300-10$ & $186 \mathrm{~h}$ \\
Fatigue Dwell & -1 & $0.3 \%$ & $0.6 \%$ & $10-300-10$ & $186 \mathrm{~h}$ \\
Fatigue & -1 & $0.2 \%$ & $0.4 \%$ & $10-0-10$ & $47 \mathrm{~h}$ \\
Fatigue & -1 & $0.2 \%$ & $0.4 \%$ & $10-0-10$ & $361 \mathrm{~h}$ \\
Fatigue & 0.05 & $0.2 \%$ & $0.19 \%$ & $10-0-10$ & $186 \mathrm{~h}$ \\
Fatigue & 0.05 & $0.3 \%$ & $0.285 \%$ & $10-0-10$ & $186 \mathrm{~h}$ \\
Fatigue Dwell & 0.05 & $0.2 \%$ & $0.19 \%$ & $10-300-10$ & $186 \mathrm{~h}$ \\
Fatigue Dwell & 0.05 & $0.3 \%$ & $0.285 \%$ & $10-300-10$ & $186 \mathrm{~h}$ \\
\hline
\end{tabular}

\section{Results}

\subsection{Strain-Free Aging: Reference Curve}

SEM images of the $\gamma^{\prime}$ precipitates coarsening after the $0 \mathrm{~h}, 144 \mathrm{~h}, 262 \mathrm{~h}$, and $429 \mathrm{~h}$ strain-free aging at $750{ }^{\circ} \mathrm{C}$ are provided in Figure 2. The corresponding PSD functions are presented in Figure 3. Except for the $429 \mathrm{~h}$ case, two Gaussian functions can systematically be fitted to the PSDs. The threshold size separating the secondary $\gamma^{\prime}$ from the tertiary $\gamma^{\prime}$ is chosen to be the size at which the Gaussian functions intersect at each other since there is always an overlapping of the fitted Gaussian functions. This intersection appears to remain constant, around $16.5 \mathrm{~nm}$, regardless of the aging duration. 


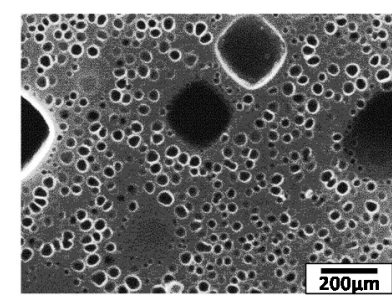

(a)

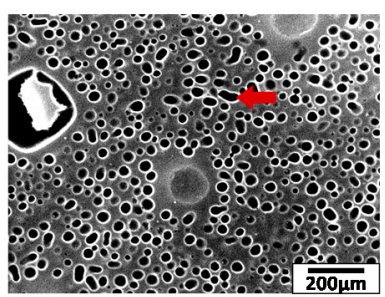

(c)

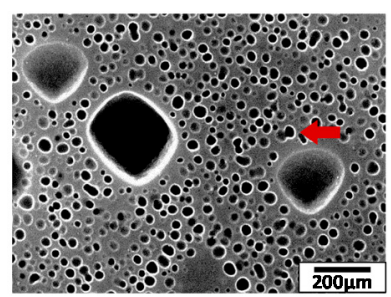

(b)

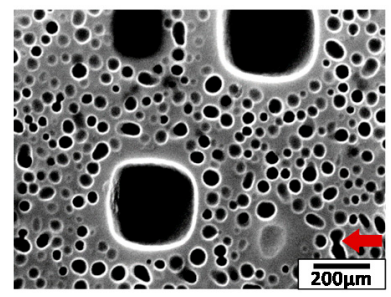

(d)

Figure 2. $\gamma^{\prime}$ evolution during strain-free aging at $750{ }^{\circ} \mathrm{C}$ with coalescing particles indicated by red arrows (FEG-SEM): (a) 0 h; (b) 144 h; (c) 262 h; (d) 429 h.

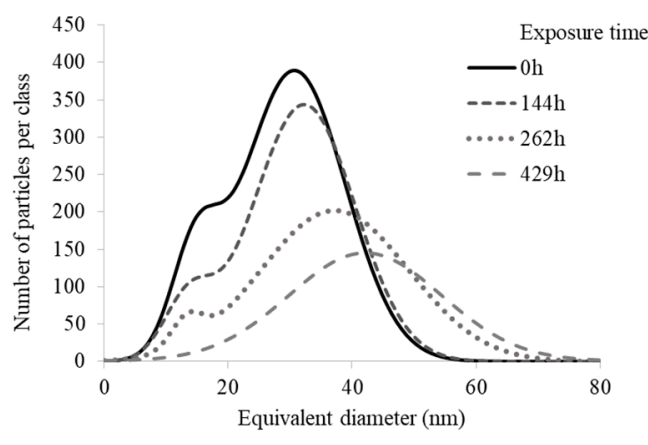

(a)

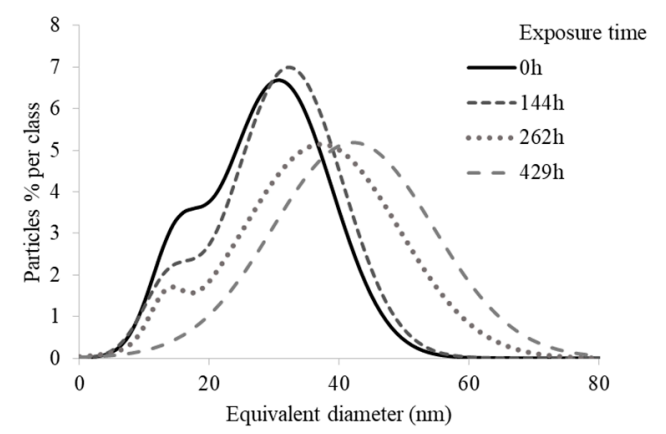

(b)

Figure 3. PSD shapes of spherical $\gamma^{\prime}$ populations after different strain-free aging time at $750{ }^{\circ} \mathrm{C}:(\mathbf{a})$ number of particles; (b) percentage of particles.

Variations with aging time of the secondary and tertiary $\gamma^{\prime}$ sizes are presented in Figure $4 a, b$, respectively. The secondary $\gamma^{\prime}$ radius increases with time, following a LSW equation in the form $[17,18]$ :

$$
<\mathrm{R}>^{3}-<\mathrm{R}_{0}>^{3}=k_{L S W} * t
$$

with $k_{L S W}$ the kinetics coefficient expressed as:

$$
k_{L S W}=\frac{8 \gamma \mathrm{DC} \infty v m}{9 R T}
$$

with $\gamma$ the interface energy, $D$ the apparent diffusion coefficient of solute atoms, $C_{\infty}$ the solute concentration at equilibrium, $v_{m}$ the solute molar volume, $R$ is the perfect gas constant and $T$ the temperature. 


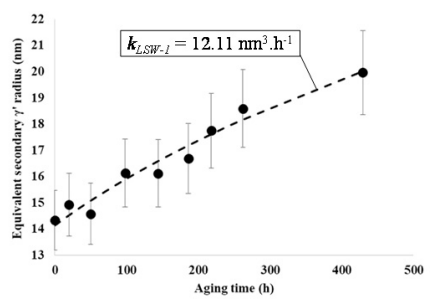

(a)

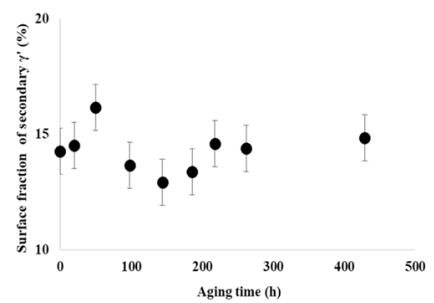

(c)

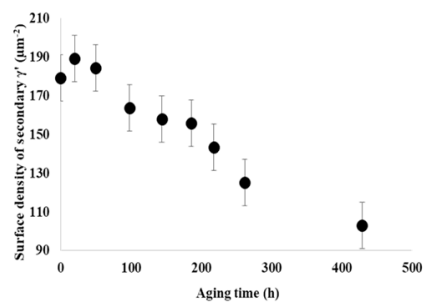

(e)

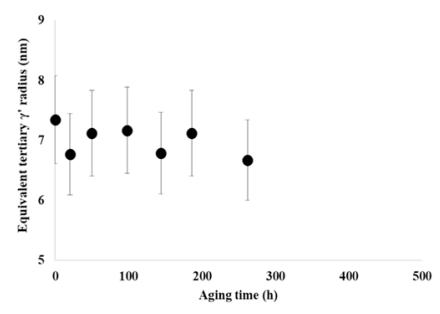

(b)

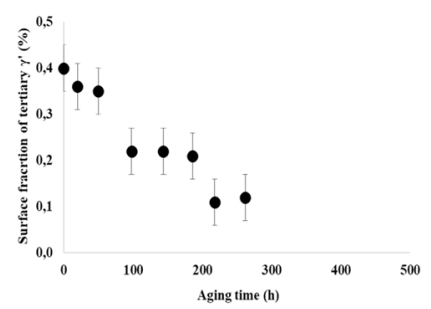

(d)

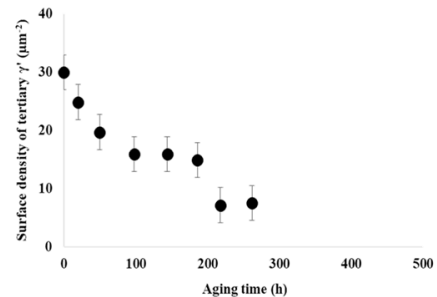

(f)

Figure 4. Evolution with aging time of: (a) the equivalent mean radius of secondary $\gamma^{\prime}$; (b) the equivalent mean radius of tertiary $\gamma^{\prime} ;$ (c) the surface fraction of secondary $\gamma^{\prime} ;(\mathbf{d})$ the surface fraction of tertiary; (e) the surface density of secondary $\gamma^{\prime} ;(\mathbf{f})$ the surface density of tertiary $\gamma^{\prime}$.

A kinetics coefficient $k_{L S W-1}=12.11 \mathrm{~nm}^{3} \cdot \mathrm{h}^{-1}$ is obtained for the $\gamma^{\prime}{ }_{\mathrm{II}}$ coarsening. Since the tertiary $\gamma^{\prime}$ sizes analyzed are within a $10 \mathrm{~nm}$ and $16.5 \mathrm{~nm}$ range, no noticeable evolution of their radius is observable. The overall spherical $\gamma^{\prime}$ population after a $429 \mathrm{~h}$ exposure time seems to be closer to a monomodal one. The mean radius is then calculated with all the spherical particles. In Figure 4 are also displayed the evolution of surface density and fraction of the two $\gamma^{\prime}$ populations. It can be seen that the surface density of these two populations decreases, reflecting the activation of the Ostwald ripening mechanism. The combination of size and surface density evolutions leads to a constant surface fraction of secondary $\gamma^{\prime}$ and a reduction in the surface fraction of tertiary $\gamma^{\prime}$.

The coalescing particles are also analyzed. Coalescing particles are already present in the initial microstructure because of the heat treatment procedure applied. The evolutions of their equivalent mean radius and surface density are presented in Figure 5. Examples of coalescing particle morphology can be found in Figure 2. The mean radius increases with time, but the surface density remains constant. A LSW equation is fitted to the evolution of coalescing particle sizes in Figure 6a, resulting in a kinetic coefficient $k_{L S W-1^{\prime}}=28.00 \mathrm{~nm}^{3} \cdot \mathrm{h}^{-1}$. 


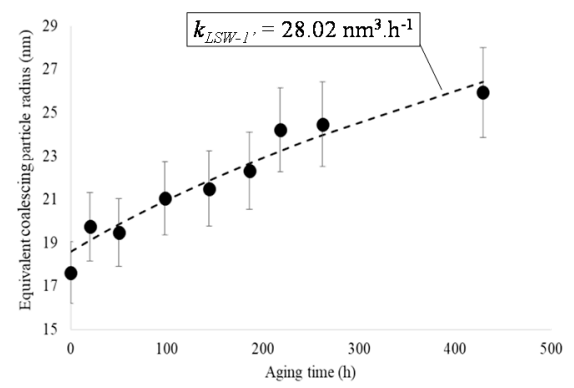

(a)

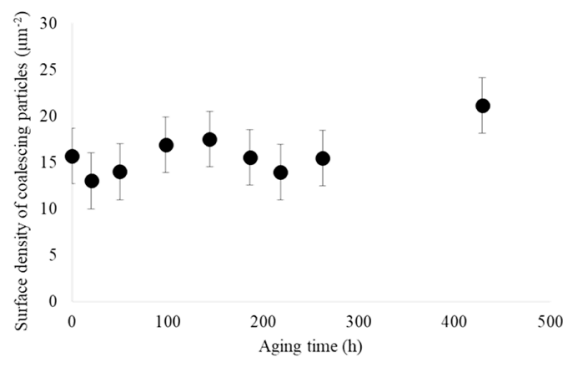

(b)

Figure 5. (a) Mean equivalent radius and (b) surface density evolutions of coalescing $\gamma^{\prime}$ particles during aging at $750{ }^{\circ} \mathrm{C}$.

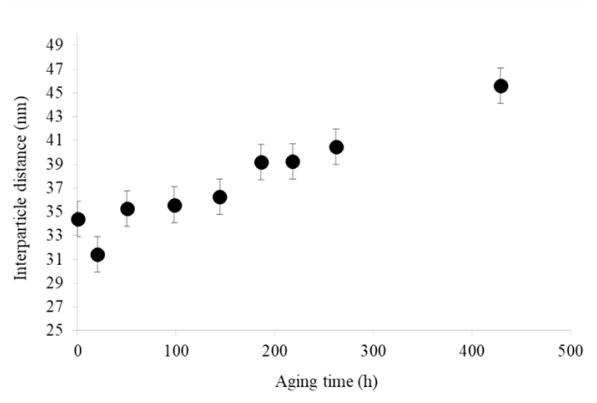

(a)

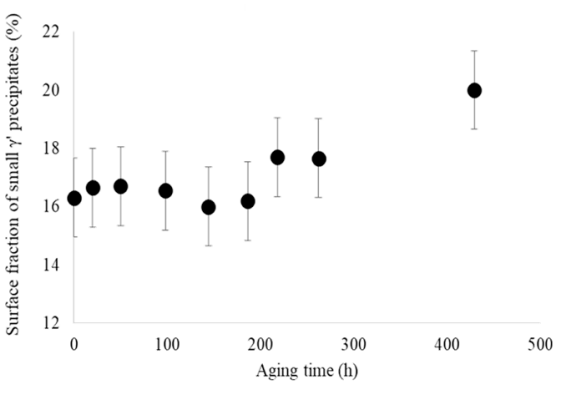

(b)

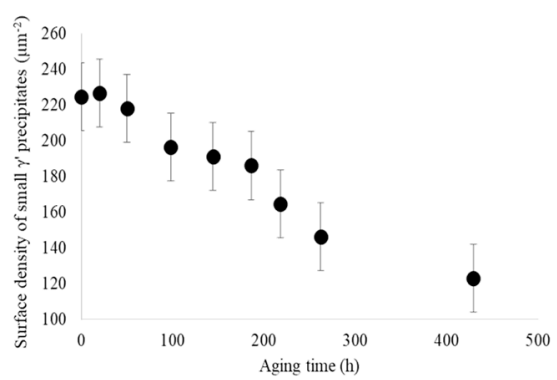

(c)

Figure 6. Evolutions of: (a) inter-particle distances; (b) total surface fraction; (c) and density of the spherical $\gamma^{\prime}$ precipitates during aging at $750{ }^{\circ} \mathrm{C}$.

When the three different $\gamma^{\prime}$ populations are considered $-\gamma_{\text {II }}^{\prime} \gamma_{\text {III }}^{\prime}$ and coalescing $\gamma^{\prime}$-the overall surface fraction of $\gamma^{\prime}$ tends to increase while the surface density decreases as it is shown in Figure 6. In Figure $6 \mathrm{a}$ is reported the evolution of the inter-particle distance between all the $\gamma^{\prime}$ precipitates. The inter-particle distance increases steadily, accounting for the dissolution of tertiary $\gamma^{\prime}$. A singular decrease is though observed at $20 \mathrm{~h}$, maybe due to a small period where a fine $\gamma^{\prime}$ population reprecipitates because of supersaturation of the matrix.

No noticeable variation of coarse cubical particles is obtained during the $750{ }^{\circ} \mathrm{C}$ aging.

\subsection{Microstructural Aging with Strain}

Most of the interrupted strain controlled-fatigue tests lead to softening behavior, with the relaxation of the maximal stress and, to a lesser extent, of the mean stress. The only condition activating macro-plasticity via an increase of the plastic strain and an opening of $\sigma v s$. $\varepsilon$ hysteresis loops is at $R_{\varepsilon}=-1$ and $\varepsilon_{\max }=0.3 \%$. 
The $\gamma^{\prime}$ stereological analysis results of the $186 \mathrm{~h}$ fatigue test specimens are shown in Figure 7. Although a fit using two Gaussian functions is realized again on the PSDs, firstly the $16.5 \mathrm{~nm}$ threshold size is retained to separate secondary and tertiary $\gamma^{\prime}$ populations and to make easier the comparison between strain-free and non-strain-free aging. Even though some scatter can be observed between the different fatigue conditions, the main trend is that the mean radiuses of secondary $\gamma^{\prime}$ are coarser after fatigue tests than after the strain-free aging. This increase goes from $3 \%$ for the lowest to $16 \%$ for the highest. No clear conclusion can be drawn from the variation of the mean sizes of tertiary $\gamma^{\prime}$ in Figure $7 \mathrm{~b}$ beside the $R_{\varepsilon}=-1$ conditions that seem to promote the dissolution of particles. The surface densities of both the secondary and tertiary populations are lower after a fatigue test, as shown in Figure $7 \mathrm{e}, \mathrm{f}$, with a $40 \%$ minimum decrease for the tertiary $\gamma^{\prime}$ surface density.

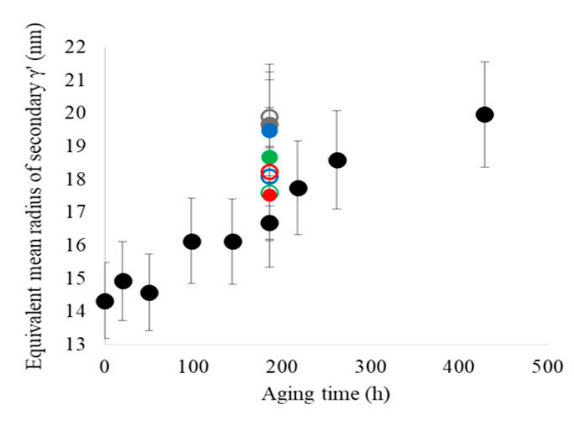

(a)

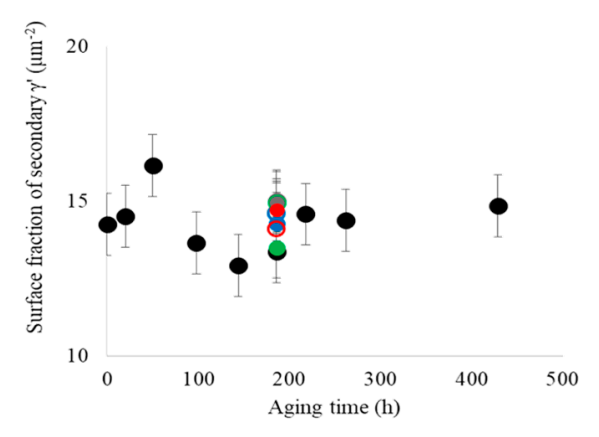

(c)

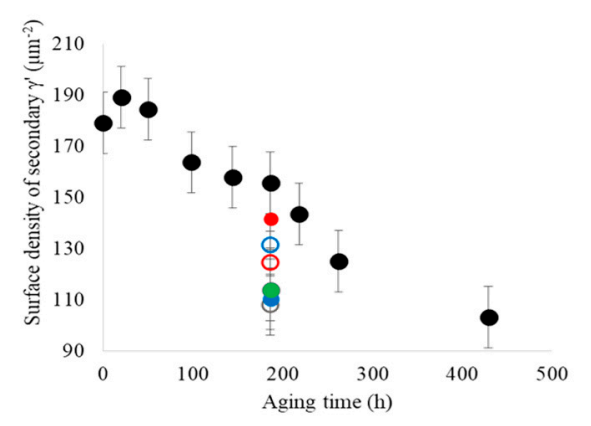

(e)

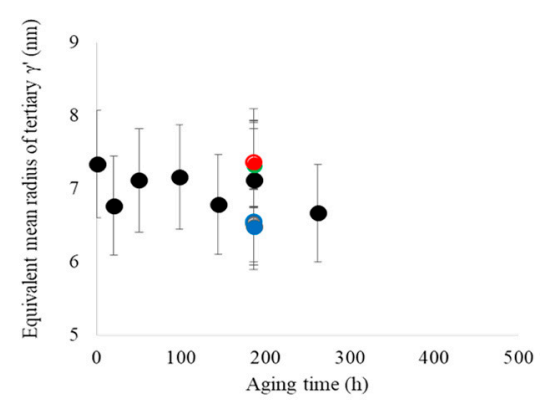

(b)

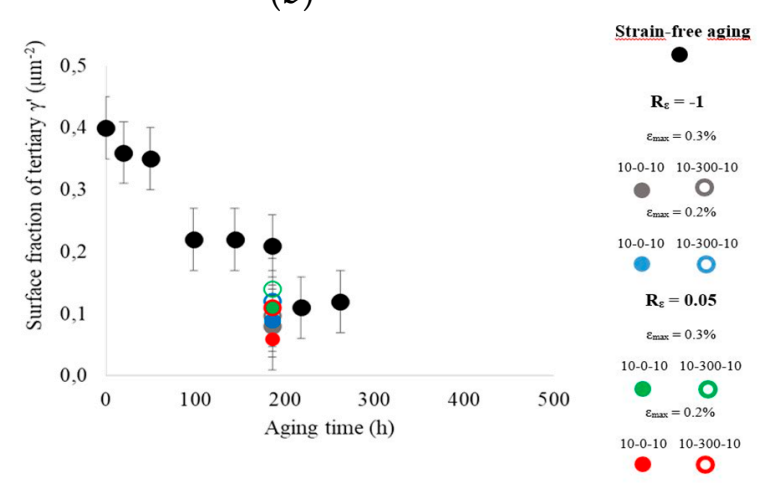

(d)

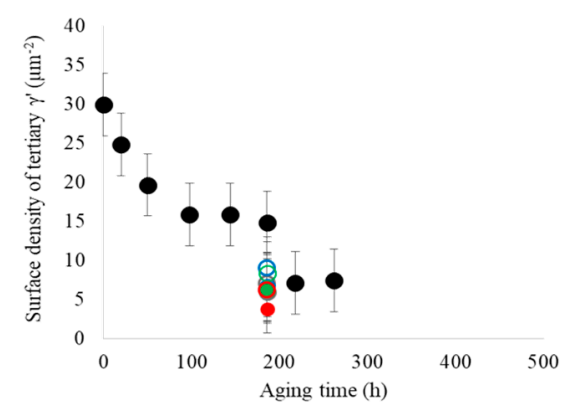

(f)

Figure 7. Evolution with aging time during strain-free aging (black) or fatigue tests (color) of: (a) the equivalent mean radius of secondary $\gamma^{\prime} ;(\mathbf{b})$ the equivalent mean radius of tertiary $\gamma^{\prime}$; (c) the surface fraction of secondary $\gamma^{\prime}$; (d) the surface fraction of tertiary; (e) the surface density of secondary $\gamma^{\prime}$; (f) the surface density of tertiary $\gamma^{\prime}$.

In order to investigate the influence of a cyclic deformation on the kinetics of precipitate growth (i.e., on $k_{L S W}$ parameter), two additional tests are performed at $R_{\varepsilon}=-1$ and $\varepsilon_{\max }=0.2 \%$ for $47 \mathrm{~h}$ and 
$361 \mathrm{~h}$, respectively. As shown in Figure 8, both tests lead to a coarser secondary $\gamma^{\prime}$ population. It is then possible to fit a LSW equation with a resulting $k_{L S W-2}=18.00 \mathrm{~nm}^{3} \cdot \mathrm{h}^{-1}, k_{L S W-2}$ being the kinetic coefficient obtained under fatigue condition. As for the determination of the strain-free LSW law, the fit of the PSDs by means of two Gaussian functions was used here.

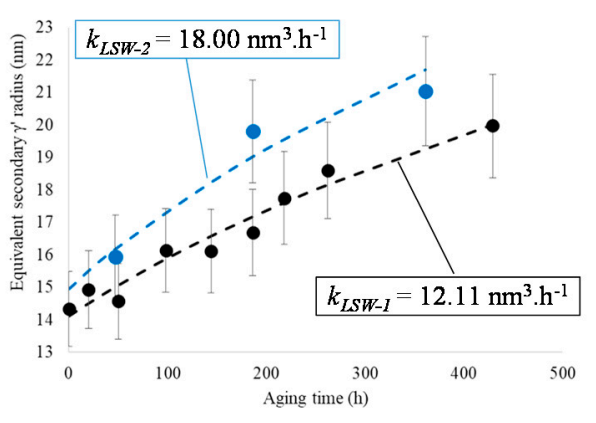

(a)

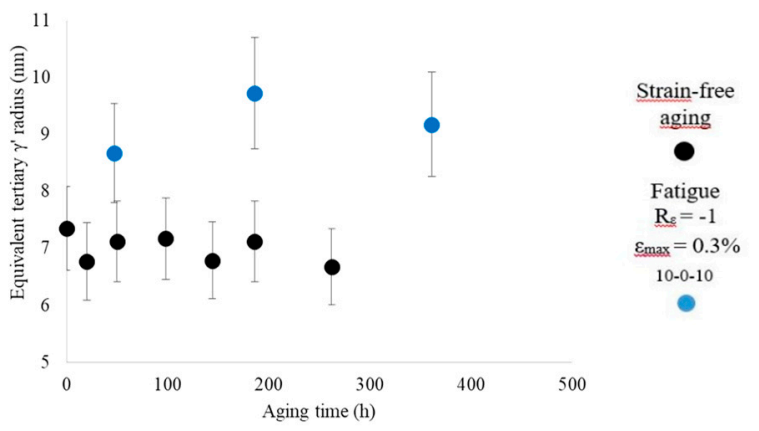

(b)

Figure 8. Equivalent mean radius evolutions after strain-free aging (black) and fatigue tests at $R_{\varepsilon}=-1-$ $\varepsilon_{\max }=0.2 \%$ (blue) at $750{ }^{\circ} \mathrm{C}$ of: (a) $\gamma^{\prime}{ }_{\text {III }} ;(\mathbf{b}) \gamma_{\text {III }}^{\prime}$.

To compare the microstructure evolution between the eight fatigue tests with a duration of 186 $\mathrm{h}$, another threshold size criterion needs to be used. As for the strain-free aging analysis, this is the intersection between the Gaussian curves fitting the secondary and tertiary $\gamma^{\prime}$ PSDs that is retained. The only difference is that, while this threshold size remains constant over the strain-free aging time, a scatter is noticed in the threshold values after the $186 \mathrm{~h}$ fatigue tests. With the use of this new threshold, the variations of the equivalent mean radius, surface fractions and densities of secondary and tertiary $\gamma^{\prime}$ can be found in Figure 9. The surface densities and fractions of each $\gamma^{\prime}$ population are normalized by the corresponding minimal value to simplify the comparison. From the mean size results in Figure 9a, it can be sorted out that both a high value of the maximal strain and a strain ratio of $R_{\varepsilon}=-1$ promote the growth of secondary $\gamma^{\prime}$. In Figure 10c, the main trends are that the dwell-fatigue 10-300-10 cycles enhance the tertiary $\gamma^{\prime}$ shrinkage at $R_{\varepsilon}=0.05$, whereas the "pure fatigue" 10-0-10 cycles enhance it at $R_{\varepsilon}=-1$. These trends are confirmed by the surface density and fraction values of tertiary $\gamma^{\prime}$ in Figure $9 \mathrm{~d}$, with lower values for the considered test conditions.

The variations in the characteristic values of coalescing particles are studied. In Figure 10a,b, the equivalent mean radiuses and the surface fractions for every aging condition are reported. Most of the fatigue conditions lead to an increase of the size of coalescing particles compared to the strain-free aging condition. As it is shown Figure 10c, the fatigue tests leading to the highest size increases are the 10-0-10 ones. The particle coarsening increase can be as high as $14 \%$ for the $10-0-10$ condition at $R_{\varepsilon}=0.05$ and $\varepsilon_{\max }=0.2 \%$. A LSW equation can be fitted to the variation of coalescing particle size during the tests with $R_{\varepsilon}=-1$ and $\varepsilon_{\max }=0.2 \%$ : the growth kinetics of the LSW equation obtained is $k_{L S W-2^{\prime}}=39.48 \mathrm{~nm}^{3} \cdot \mathrm{h}^{-1}$. In Figure $10 \mathrm{~b}$,d, it can be seen that the surface densities vary according to the strain cycling conditions. Indeed, the 10-0-10 tests lead to lower surface densities while the 10-300-10 tests result in much higher surface densities with increases as high as $40 \%$ compared to the strain-free results.

Finally, some parallels can be drawn between fatigue behaviors and the resulting microstructure:

- In Figure 11a, the increase in mean sizes of secondary $\gamma^{\prime}$ is related to the average stress amplitudes during testing as well as the slight decrease in tertiary $\gamma^{\prime}$ size in Figure 11b. It should be noted that the correlations are the same when plotted versus strain rates. Indeed, loading and unloading durations being kept constant at $10 \mathrm{~s}$, the higher the strain/stress amplitudes, the higher the strain rates. 
- Figure $11 \mathrm{c}, \mathrm{d}$ deal with coalescing particles: they respectively show the decrease in mean size and the increase in surface fraction as a function of the mean stress during the $186 \mathrm{~h}$ fatigue tests. The mean stress used is the averaged value over time. Regarding the dwell-fatigue conditions, since $94 \%$ of the test duration is spent at maximal stress, the mean stress is considered to be the average maximal stress throughout the test.

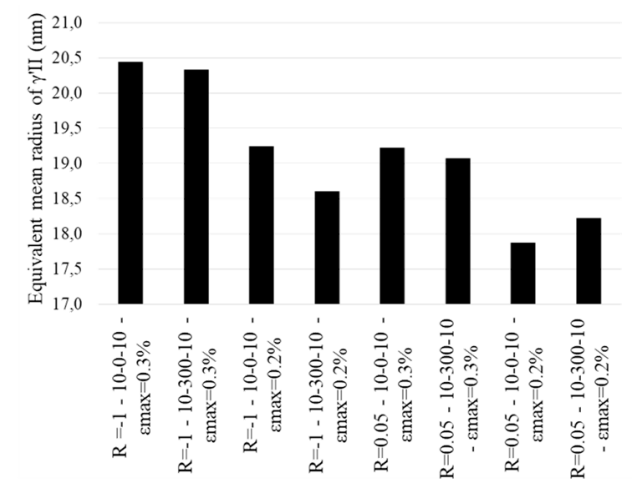

(a)

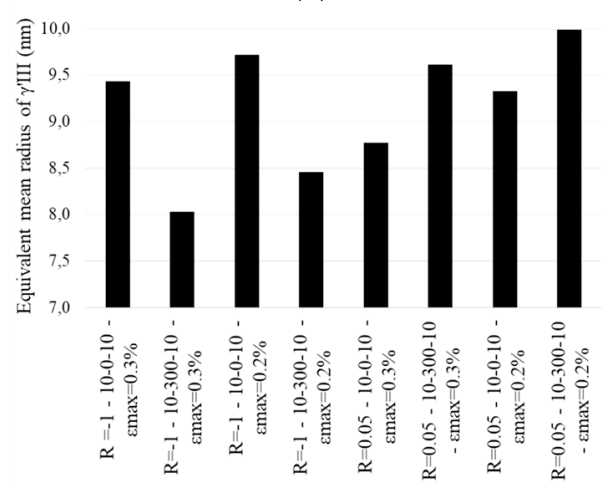

(c)

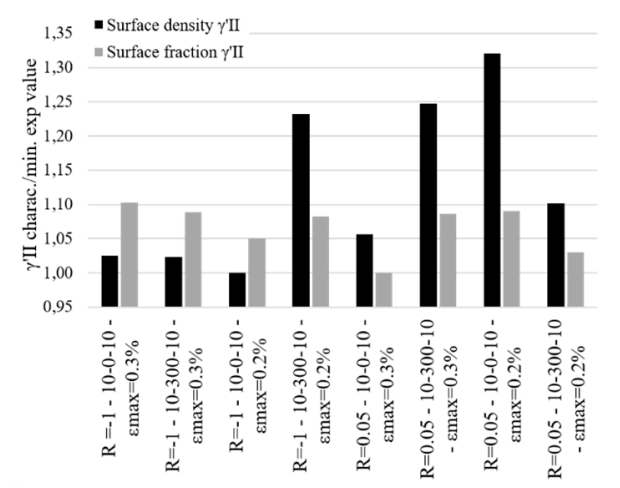

(b)

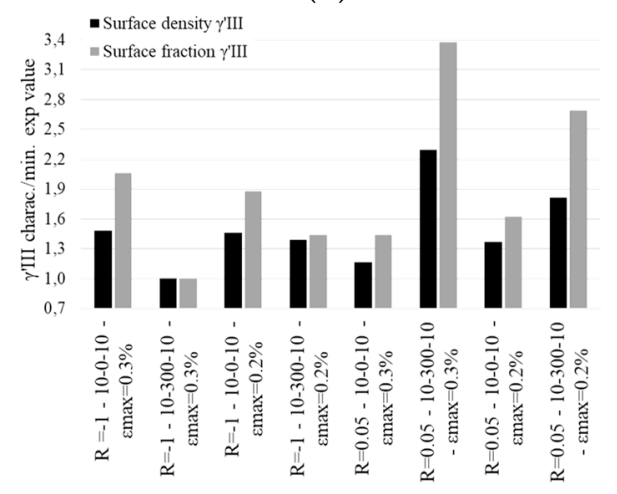

(d)

Figure 9. After the $186 \mathrm{~h}$ fatigue tests, (a) Equivalent mean radius of secondary $\gamma^{\prime}$; (b) Surface density and fraction normalized by the corresponding minimal value for the secondary $\gamma^{\prime} ;$ (c) Equivalent mean radius of tertiary $\gamma^{\prime}$; (d) Surface density and fraction normalized by the corresponding minimal value for the tertiary $\gamma^{\prime}$. 


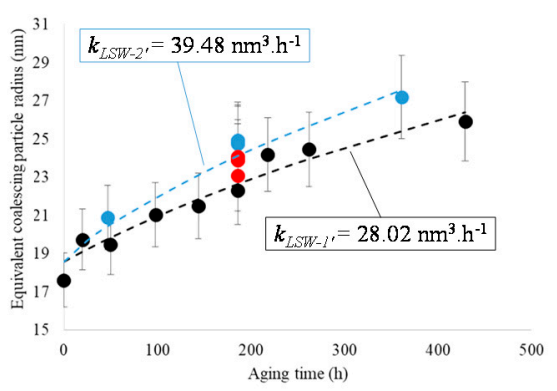

(a)

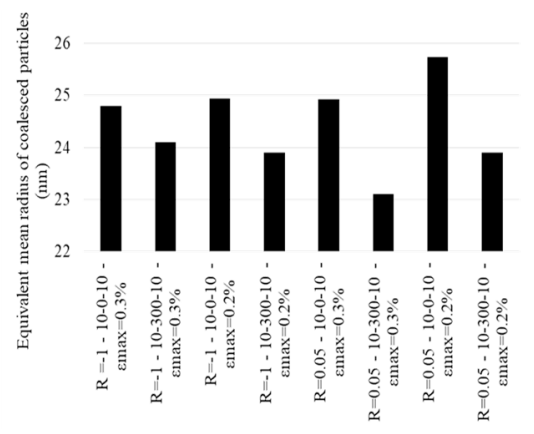

(c)

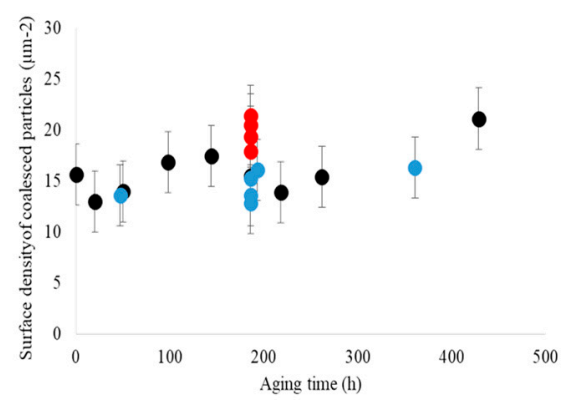

(b)

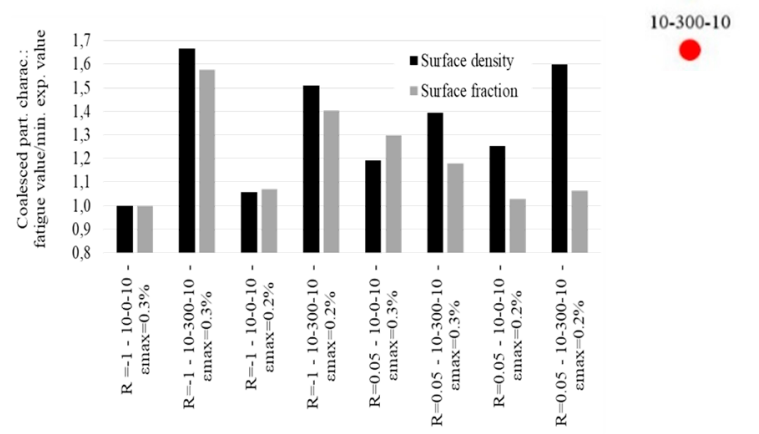

(d)

Figure 10. Evolution of coalescing particle: (a) radius; (b) surface fractions; after strain-free aging (black), fatigue tests with 10-0-10 cycles (blue) and 10-300-10 cycles (red). Comparison of the particle characteristics between the different $186 \mathrm{~h}$ fatigue test conditions: (c) mean radius; (d) surface fraction and density. 


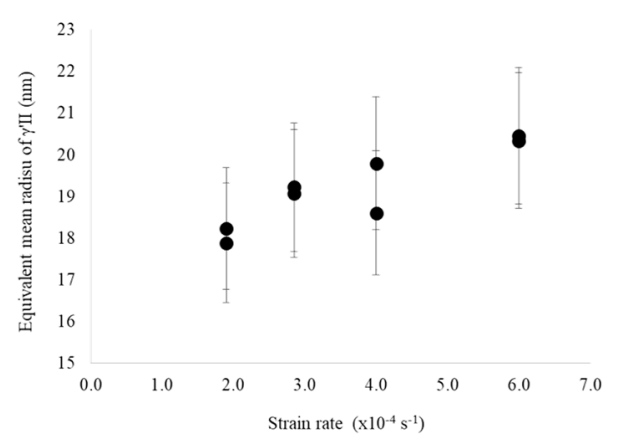

(a)

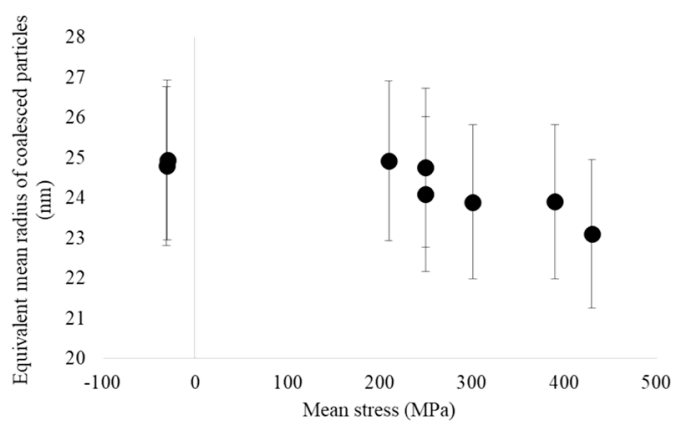

(c)

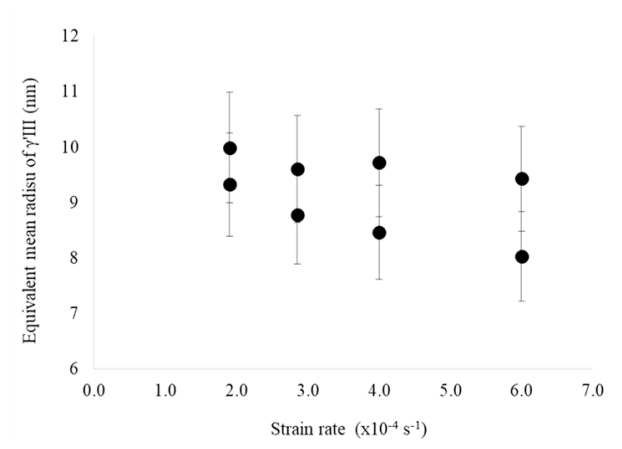

(b)

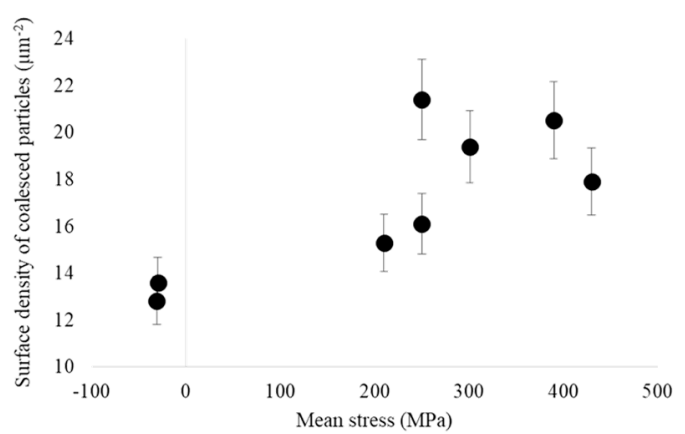

(d)

Figure 11. Evolution during the $186 \mathrm{~h}$ fatigue tests of the equivalent mean radiuses with the strain rate

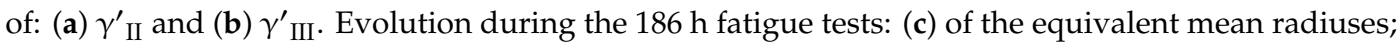
(d) surface densities of coalescing particles with the mean stress.

\section{Discussion}

The aging of $\gamma^{\prime}$ precipitation at $750{ }^{\circ} \mathrm{C}$ with and without cyclic applied strain has been investigated. Regarding the results presented above, several topics are being discussed now. A focus is first made on the importance of the criterion used to determine the threshold size dissociating the secondary and tertiary $\gamma^{\prime}$ populations. Then, the mechanism of coalescence during the strain-free aging and the influence of fatigue cycling on the $\gamma^{\prime}$ aging are discussed in deeper details.

\subsection{Choice of the Threshold Size}

Beside the agreement between the fitted LSW law and the increase of secondary $\gamma^{\prime}$ size experimentally determined during the strain-free aging (Figure 4a), the other main evidence that an Ostwald ripening mechanism is taking place at $750{ }^{\circ} \mathrm{C}$ in then $\mathrm{AD} 730^{\mathrm{TM}}$ is the decrease observed in the tertiary $\gamma^{\prime}$ surface density (Figure $4 \mathrm{f}$ ). For the strain-free aging analysis, the criterion chosen to discriminate the $\gamma_{\text {II }}^{\prime}$ and $\gamma_{\text {III }}^{\prime}$ populations, i.e., the intersection between the two fitted Gaussian functions, can however be discussed.

Indeed, in the Ostwald ripening theory and considering a homogeneous monomodal particle population, the critical radius $R^{*}$ below which particles shrink and above which particles grow, is the mean size $<R>$ of the population [14,15,61]. In the present study, while not shown in the present paper, it was noticed that the use of the mean size of all the spherical $\gamma^{\prime}$ precipitates does not end up in any meaningful tendency. Several reasons explain this observation. On the one hand, the initial state of the spherical $\gamma^{\prime}$ population is not monomodal and, moreover, exhibits an overlapping between the two $\gamma_{\text {II }}^{\prime}$ and $\gamma_{\text {III }}^{\prime}$ populations (Figure 3). On the other hand, the spatial distribution of the tertiary $\gamma^{\prime}$ is not homogeneous. Indeed, as shown Figure $1 \mathrm{c}$, most of the $\gamma^{\prime}$ III surround the coarse cubical $\gamma^{\prime}$. The reason is that this small population of $\gamma^{\prime}$ is the last one to precipitate during the heat-treatment, while the first population to precipitate is the cubical one [7]. The tertiary $\gamma^{\prime}$ population precipitates after $800^{\circ} \mathrm{C} / 4 \mathrm{~h}$ 
annealing and upon cooling. As for any precipitation mechanism, the thermodynamic driving force for the $\gamma^{\prime}$ III to precipitate is the supersaturation in $\gamma^{\prime}$-forming elements (Al, Ti). Thus, when the secondary $\gamma^{\prime}$ population has precipitated, the regions where $\gamma^{\prime}$-forming elements are the most abundant during the two subsequent annealing treatments are located in the neighborhood of the cubical $\gamma^{\prime}$. The spatial distribution of tertiary $\gamma^{\prime}$ ultimately ends to be localized and not homogeneous. It is then possible that the Ostwald ripening process does not take place immediately in all the microstructure volume, but first around the cubical $\gamma^{\prime}$ particles. This assumption cannot be readily confirmed by image analysis and is not clearly observable in the microstructure frames in Figure 2. It must be recalled eventually that the Ostwald ripening theory relies on the hypothesis of a near-zero $\gamma^{\prime}$ volume fraction [17].

All things considered, since the intersection of the two fitted Gaussians remains fairly stable during the strain-free aging, this criterion is assumed to be a relevant one for the present purpose.

\subsection{Coalescence Thermally and Time Dependent}

Regarding the coalescing particles, a LSW equation can also be fitted to their size variation over aging time with a coarsening rate of $28.00 \mathrm{~nm}^{3} \cdot \mathrm{h}^{-1}$. For the record, the coalescence occurs in two steps with no change in the $\gamma^{\prime}$ phase volume involved: (1) necking between at least two precipitates; (2) formation of one coarser spherical precipitate. When we consider the LSW kinetics associated to the growth of particles whose volume is twice the one of spherical $\gamma^{\prime}$ precipitates, we obtain a theoretical $k_{L S W}$ of about $21.84 \mathrm{~nm}^{3} \cdot \mathrm{h}^{-1}$ instead of the experimental $28.00 \mathrm{~nm}^{3} \cdot \mathrm{h}^{-1}$. The main reason accounting for this result is that the coalescing particles analyzed can also be constituted of more than two bonded particles. We determine that the average coalescing particles is made of 2.3 spherical precipitates.

Till $300 \mathrm{~h}$ of aging at $750{ }^{\circ} \mathrm{C}$, the surface density of coalescing precipitates does not noticeably increase (Figure $5 b$ ), meaning that the rate of necking between particles is equal to the rate of formation of a coalesced particle in its final state (i.e., a spherical precipitate). The temperature of $750{ }^{\circ} \mathrm{C}$ is sufficient to activate the coalescence mechanism in the AD730 ${ }^{\mathrm{TM}}$. However, it seems from Figure 5b that the surface density increases between $300 \mathrm{~h}$ and $400 \mathrm{~h}$ of aging. The $\gamma^{\prime}$ microstructure has reached a state where the kinetics of coalescence between particles is increasing, leading to more coalescing particles observed. Through this result, we can assert that coalescence is indirectly time-dependent in which it is influenced by the microstructure aging itself. One of the explanations relies on the concomitance of the coarsening and coalescence mechanisms. At $400 \mathrm{~h}$, the very small precipitates (e.g., tertiary $\gamma^{\prime}$ ) required for the Ostwald ripening of coarser precipitates are very few. To ensure the reduction in total interfacial energy, the coalescence rate increases.

\subsection{Thermomechanical Contribution to Aging Mechanisms?}

As shown in Figure 10, when a cyclic strain is applied and, in the present case, within the macroscopic elastic domain, the LSW coarsening kinetics of $\gamma_{\text {II }}^{\prime}$ and coalescing precipitates are increased. The ratios between the LSW kinetic coefficients obtained during the fatigue condition $R_{\varepsilon}=-1$ and $\varepsilon_{\max }=0.2 \%$ and the strain-free conditions are: $\frac{k_{\mathrm{LSW}-2}}{k_{\mathrm{LSW}-1}}=\frac{18.00}{12.11}=1.49$ for the $\gamma_{\mathrm{II}}^{\prime}$ coarsening. Based on Equation (2), the physical quantities that may be influenced by cyclic strain/stress at $750{ }^{\circ} \mathrm{C}$ are the surface energy $\gamma$ via a change in the constraint $\gamma / \gamma^{\prime}$ lattice misfit, the diffusion coefficient $D$ [37], and the solute equilibrium concentration $C_{\infty}$ [60]. For the former, the impact of the strain/stress leads to a decrease of the constraint misfit [34,36], which is slightly negative in the AD730 ${ }^{\mathrm{TM}}$ as shown by Durand in its PhD thesis works [62]. The subsequent reduction in the coherency between the $\gamma$ and $\gamma^{\prime}$ phases causes a drop in the precipitate stability, enhancing Ostwald ripening kinetics [45]. The applied strain also has an effect on the lattice itself, the deformation easing the diffusion of $\gamma^{\prime}$-forming elements in the $\gamma$ matrix, notably via the increase in vacancy density [63-67]. Even though most of the fatigue conditions tested do not activate macro-plasticity, dislocation movements can still be initiated and consequently act as diffusion paths for elements, enabling the "pipe diffusion" mechanism [35,39,41,43,44]. Eventually, Johnson showed in his work from 1987 that the solute equilibrium concentration around precipitates can differ between the strained and strain-free conditions [68]. Thus, this is most likely the increase 
in volume diffusion of $\gamma^{\prime}$-forming elements thanks to lattice deformation and "pipe diffusion" that is enhanced under fatigue loading. Establishing another LSW equation with additional fatigue test conditions (i.e., fatigue tests with the same applied strain amplitudes but with different durations) would give further clues to understand the effect of a cyclic strain on the LSW kinetic coefficient $k_{L S W}$. Following these observations, the result shown Figure 9 a by which the higher the maximal imposed strain $\varepsilon_{\max }$, the higher the $\gamma^{\prime}{ }_{\text {II }}$ coarsening kinetics, was then expected.

In the same way, a strain ratio of $R_{\varepsilon}=-1$ is more efficient in enhancing the coarsening kinetics than $R_{\varepsilon}=0.05$. However this effect is not to be related to the average mean stress, but rather to the average stress amplitude, and consequently to the strain rate as shown Figure 11a. Two factors, maybe synergistically, are responsible for this result:

- The first one is that a high strain rate leads to a more difficult accommodation of stress and strain fields surrounding the precipitates, leading to a slightly higher instability of the $\gamma / \gamma^{\prime}$ interface and promoting the Ostwald ripening phenomenon. This is supported by the fact that, in most cases, the introduction of a $300 \mathrm{~s}$ dwell-period at maximal strain tones down the increase in aging kinetics: dwell-periods allow the near-precipitate lattice to accommodate the changes in strain and stress local fields.

- The second one is that diffusion coefficients of elements are linearly dependent on the strain rate. Girifalco et al., Forestieri et al., and Angiolini et al. $[63,64,66]$ established this result on silver and $\mathrm{Cu}-\mathrm{Zn}$ alloys. Indeed, the diffusion coefficient under strain $(D s)$ can be written as following an Arrhenius law (Equation (3)) related to the strain value imposed (s), the activation energy per unit strain $\left(Q^{\prime}\right)$ and the diffusion coefficient in strain-free conditions $(D)$ [69].

$$
D_{S}=D \mathrm{e}^{\frac{-Q / s}{k T}}
$$

The role of the compressive loading phases in the $\gamma^{\prime}{ }_{\text {II }}$ coarsening kinetics increase during $R_{\varepsilon}=$ -1 tests is not fully understood yet, but works on a single crystal Ni-Al alloy from Prikhodko et al., suggest that compressive stresses at $640{ }^{\circ} \mathrm{C}$ slow down the coarsening kinetics of precipitates [70]. The Equation (3) also suggests that a compressive strain increases the diffusion coefficient, hence the aging kinetics. On their work on the effect of linear friction welding on the microstructure changes of a nickel-based superalloy, Ola et al. shows on this basis that the dissolution rate of $\gamma^{\prime}$ precipitates is increased in the zone affected both by temperature and compressive loading.

Regarding the coalescing particle population, the main fatigue parameter influencing its changes over time is the cycle waveform. The dwell-fatigue tests with 10-300-10 cycles lead to higher surface densities while the 10-0-10 tests have no effect on that (Figure 10d). Therefore, it can be asserted that 10-300-10 conditions accelerate the rate of coalescence between precipitates at $750{ }^{\circ} \mathrm{C}$. The fatigue parameter that accounts for these observations is the mean stress (temporal average), with the mean stress of the 10-300-10 tests being close to the maximal stress (Figure 11c,d). High mean stresses provide the conditions for the coalescence rate to increase during fatigue tests, for instance thanks to a greater dislocation density at the $\gamma / \gamma^{\prime}$ interface [33].

\section{Conclusions}

From the study of the coarse-grained $\mathrm{AD} 730^{\mathrm{TM}}$ microstructure aging during strain-free exposure or strain-controlled cyclic loading at $750{ }^{\circ} \mathrm{C}$, the main conclusions are:

(1) Strain-free aging at $750{ }^{\circ} \mathrm{C}$ activates two concomitant microstructure aging mechanisms: the coarsening and the coalescence of $\gamma^{\prime}$. The spherical $\gamma_{\text {II }}^{\prime}$ precipitates coarsen via a thermally activated Ostwald ripening process following a cubic LSW equation. This coarsening takes place at the expense of the small tertiary $\gamma^{\prime}$ that end up by being completely dissolved. The inter-particle distance then increases during the aging. The coalescence of precipitates and particularly the 
necking rate between them remains steady during strain-free aging, but can increase when small precipitates involved in Ostwald ripening are getting fewer.

(2) Aging mechanisms are not only thermally controlled, but also mechanically controlled:

- When a cyclic strain is applied, the Ostwald ripening kinetics is enhanced. The main reasons are the effect of stress/strain on the misfit, the increase in the $\gamma / \gamma^{\prime}$ interface energy, and the $\gamma^{\prime}$-forming element diffusion through the $\gamma$ matrix, promoted by lattice deformation and "pipe diffusion" via dislocations. Hence, it has been shown that the higher the maximal strain, the greater the $\gamma^{\prime}$ coarsening kinetics.

- A strain ratio of -1 compared to 0.05 is more efficient in enhancing the coarsening kinetics. That is, because the coarsening of $\gamma_{\text {II }}^{\prime}$ precipitates depends on the stress amplitude and the strain rate.

- Moreover, 10-300-10 dwell-fatigue loading is less efficient to increase the coarsening kinetics compared to the 10-0-10 fatigue loading, thanks to a better accommodation of the deformation in dwell conditions.

- Dwell-fatigue increases the coalescence rate of $\gamma^{\prime}$ particles at $750{ }^{\circ} \mathrm{C}$ due to the applied high mean stress. Fatigue loading with low mean stresses does not increase $\gamma^{\prime}$ coalescence kinetics compared to strain-free conditions.

Author Contributions: Conceptualization, G.H., P.V., J.C., and N.M.; Methodology, F.H., J.C., and N.M..; Validation, G.H., P.V., A.-L.R., and J.-M.F.; Formal analysis, N.M.; Investigation, J.C. and N.M.; Writing-original draft preparation, N.M.; Writing—review and editing, G.H., J.C., A.-L.R., J.-M.F., and N.M.; Supervision, G.H., P.V., A.-L.R., and J.-M.F.; Funding acquisition, J.C. and P.V. All authors have read and agreed to the published version of the manuscript.

Funding: The work received financial support from the French Agency for Scientific Research (ANR) and from the Safran group via industrial chair ANR-Safran OPALE (grant number ANR-14-CHIN-0002).

Conflicts of Interest: The authors declare no conflicts of interest.

\section{References}

1. Radis, R.; Schaffer, M.; Albu, M.; Kothleitner, G.; Pölt, P.; Kozeschnik, E. Evolution of size and morphology of $\gamma^{\prime}$ precipitates in Udimet $720 \mathrm{Li}$ during continuous cooling. In Proceedings of the 11th International Symposium, Seven Springs, PA, USA, 14-18 September 2008; pp. 829-836.

2. Pollock, T.M.; Tin, S. Nickel-Based Superalloys for Advanced Turbine Engines: Chemistry, Microstructure, and Properties. J. Propuls. Power 2006, 22, 361-374. [CrossRef]

3. Thébaud, L.; Villechaise, P.; Cormier, J.; Hamon, F.; Crozet, C.; Devaux, D.; Franchet, J.M.; Rouffié, A.L.; Organista, A. Relationships between microstructural parameters and time-dependent mechanical properties of a new nickel based AD730TM. In Proceedings of the 13th International Symposium on Superalloys, Seven Springs, PA, USA, 11-15 September 2016; pp. 877-886.

4. Devaux, A.; Picqué, B.; Gervais, M.F.; Georges, E.; Poulain, T.; Héritier, P. AD730 ${ }^{\mathrm{TM}}$, a new nickel-based superalloy for high temperature engine rotative parts. In Proceedings of the International Symposium on Superalloys, Seven Springs, PA, USA, 9-13 September 2012; pp. 911-919.

5. Benyoucef, M.; Coujou, A.; Barbker, B.; Clement, N. In situ deformation experiments on a $\gamma / \gamma^{\prime}$ superalloy. Strengthening mechanisms. Mater. Sci. Eng. A 1997, 234, 692-694. [CrossRef]

6. Jackson, M.P.; Reed, R.C. Heat treatment of Udimet 720Li: The effect of microstructure on properties. Mater. Sci. Eng. A 1999, 259, 85-97. [CrossRef]

7. Masoumi, F.; Shahriari, D.; Jahazi, M.; Cormier, J.; Devaux, A. Kinetics and Mechanisms of $\gamma^{\prime}$ Reprecipitation in a Ni-based Superalloy. Sci. Rep. 2016, 6, 1-16. [CrossRef] [PubMed]

8. Goodfellow, A.; Galindo-Nava, E.; Christofidou, K.; Jones, N.; Martin, T.; Bagot, P.; Boyer, C.; Hardy, M.; Stone, M. Gamma prime precipitate evolution during aging of a model nickel-based superalloy. Metall. Mater. Trans. A 2017, 49, 718-728. [CrossRef] 
9. Torster, F.; Baumeister, G.; Albrecht, J.; Lütjering, G.; Helm, D.; Daeubler, M. Influence of grain size and heat treatment on the microstructure and mechanical properties of the nickel-base superalloy U 720 LI. Mater. Sci. Eng. A 1997, 234, 189-192. [CrossRef]

10. Hardy, S.; Voorhees, P. Ostwald Ripening in a System with a High Volume Fraction of Coarsening Phase. Metall. Trans. A 1988, 19A, 2713-2721.

11. Devaux, A.; Helstroffer, A.; Cormier, J.; Villechaise, P.; Douin, J.; Hantcherli, M.; Pettinari-Sturmel, F. Effect of aging heat-treatment on mechanical properties of AD730TM superalloy. In Proceedings of the 8th International Symposium on Superalloy 718 and Derivatives, Pittsburgh, PA, USA, 28 September-1 October 2014; pp. 521-535.

12. Telesman, J.; Kantzos, P.; Gayda, J.; Bonacuse, P.J.; Prescenzi, A. Microstructural variables controlling time-dependent crack growth in a $\mathrm{P} / \mathrm{M}$ superalloy. In Proceedings of the International Symposium, Seven Springs, PA, USA, 19-23 September 2004; pp. 215-224.

13. Grosdidier, T.; Hazotte, A.; Simon, A. Precipitation and dissolution processes in $\gamma / \gamma^{\prime}$ single crystal nickel-based superalloys. Mater. Sci. Eng. 1998, A256, 183-196. [CrossRef]

14. Voorhees, P. Ostwald ripening of two-phase mixtures. Annu. Rev. Mater. Sci. 1992, 22, 197-215. [CrossRef]

15. Wang, Q.; Robert, F.; Xu, H.; Li, X. On the critical radius in generalized Ostwald ripening. J. Zhejiang Univ. Sci. 2005, 6B, 705-707. [CrossRef]

16. Marder, M. Correlations and Ostwald ripening. Phys. Rev. A 1987, 36, 858-874. [CrossRef] [PubMed]

17. Baldan, A. Review: Progress in Ostwald ripening theories and their applications to the $\gamma^{\prime}$-precipitates in nickel-base superalloys-Part I: Ostwald ripening theories. J. Mater. Sci. 2002, 37, 2171-2202. [CrossRef]

18. Baldan, A. Review: Progress in Ostwald ripening theories and their applications to the $\gamma^{\prime}$-precipitates in nickel-base superalloys-Part II: Nickel-base superalloys. J. Mater. Sci. 2002, 37, 2379-2405. [CrossRef]

19. Ardell, A. Interfacial Free Energies and Solute Diffusivities from Data on Ostwald Ripening. Interface Sci. 1995, 3, 119-125. [CrossRef]

20. Ardell, A.; Ozolins, V. Trans-interface diffusion-controlled coarsening. Nat. Mater. 2005, 4, 309-316. [CrossRef]

21. Ardell, A. Trans-interface-diffusion-controlled coarsening of $\gamma^{\prime}$ precipitates in ternary Ni-Al-Cr alloys. Acta Mater. 2013, 61, 7828-7840. [CrossRef]

22. Brailsford, A.; Wynblatt, P. The dependence of Ostwald ripening kinetics on particle volume fraction. Acta Meter. 1979, 27, 489-497. [CrossRef]

23. Lifshitz, I.; Slyozov, V. The kinetics of precipitation from supersaturated solid solutions. J. Phys. Chem. Solids 1961, 19, 35-50. [CrossRef]

24. Wagner, C. Theory of precipitate change by redissolution. Z. Electrochem. 1961, 65, 581-591.

25. Tiley, J.; Viswanathan, G.; Srinivasan, R.; Banerjee, R.; Dimiduk, D.; Fraser, H. Coarsening kinetics of $\gamma^{\prime}$ precipitates in the commercial nickel base Superalloy Rene' 88 DT. Acta Mater. 2009, 57, 2538-2549. [CrossRef]

26. Moore, I.; Burke, M.; Nuhfer, N.; Palmiere, E. Evaluation of classical precipitation descriptions for $\gamma^{\prime \prime}$ $\left(\mathrm{Ni3Nb}-\mathrm{D0}_{22}\right)$ in Ni-base superalloys. J. Mater. Sci. 2017, 52, 8665-8680. [CrossRef] [PubMed]

27. Laurence, A.; Cormier, J.; Villechaise, P.; Billot, T.; Franchet, J.M.; Pettinari-Sturmel, F.; Hantcherli, M.; Mompiou, F.; Wessman, A. Impact of the solution cooling rate and of thermal aging on the reep properties of the new cast and wrought René 65 Ni-based superalloy. In Proceedings of the 8th International Symposium on Superalloy 718 and Derivatives, Pittsburgh, PA, USA, 28 September-1 October 2014; pp. 333-348.

28. Mataveli Suave, L.; Cormier, J.; Villechaise, P.; Soula, A.; Hervier, Z.; Bertheau, D.; Laigo, J. Microstructural evolutions during thermal aging of alloy 625: Impact of temperature and forming process. Mater. Trans. A 2014, 45, 2963-2982. [CrossRef]

29. Mukherjee, K.; Hsu, T.; Kato, M. Fiber morphology resulting from solid state coalescence of spherical precipitates. Phys. Stat. Solidi 1984, 81, 439-444. [CrossRef]

30. Mao, Z.; Sudbrack, C.; Yoon, K.; Martin, G.; Seidman, D. The mechanism of morphogenesis in a phase-separating concentrated multicomponent alloy. Nat. Mater. 2007, 6, 210-216. [CrossRef] [PubMed]

31. Masoumi, F.; Jahazi, M.; Shahriari, D.; Cormier, J. Coarsening and dissolution of $\gamma^{\prime}$ precipitates during solution treatment of AD730 ${ }^{\mathrm{TM}} \mathrm{Ni}$-absed superalloy: Mechanisms and kinetics models. J. Alloys Compd. 2016, 658, 981-995. [CrossRef]

32. Wang, T.; Sheng, G.; Liu, Z.; Chen, L. Coarsening kinetics of $\gamma^{\prime}$ precipitates in the Ni-Al-Mo. Syst. Acta Mater. 2008, 56, 5544-5551. [CrossRef] 
33. Hisazawa, H.; Terada, Y.; Takeyama, M. Morphology evolution of $\mathrm{y}^{\prime}$ precipitates during isothermal exposure in wrought Ni-based superalloy Inconel X-750. Mater. Trans. 2017, 58, 817-824. [CrossRef]

34. Pollock, T.; Argon, A. Directional coarsening in nickel-base single crystals with high volume fractions of coherent precipitates. Acta Mater. 1993, 42, 1859-1874. [CrossRef]

35. Sauthoff, G. Influence of stresses on precipitation. J. Phys. Coll. 1996, C1, 87-97. [CrossRef]

36. Mughrabi, H. Microstructural aspects of high temperature deformation of monocrystalline nickel base superalloys: Some open problems. Mater. Sci. Technol. 2009, 25, 191-204. [CrossRef]

37. Flageolet, B. Effet Du Vieillissement Du Superalliage Base Nickel N18 Pour Disques de Turbines Sur Sa Durabilité en Fatigue Et Fatigue-Fluage à $700{ }^{\circ} \mathrm{C}$. Ph.D. Thesis, ISAE ENSMA, Poitou-Charentes, France, 2005.

38. Wu, C. The role of Eshelby stress in compoposition-generated and stress-assisted diffusion. J. Mech. Phys. 2001, 49, 1771-1794. [CrossRef]

39. Kolbe, M.; Dlouhy, A.; Eggeler, G. Dislocation reactions at $\gamma / \gamma^{\prime}$-interfaces during shear creep deformation in the macroscopic crystallographic shear system (001)of CMSX6 superalloy single crystals at $1025^{\circ} \mathrm{C}$. Mater. Sci. Eng. 1998, A246, 133-142. [CrossRef]

40. Nabarro, F. Rafting in superalloys. Metall. Mater. Trans. A 1996, 27A, 513-530. [CrossRef]

41. Kontis, P.; Li, Z.; Collins, D.; Cormier, J.; Raabe, D.; Gault, B. The effect of chromium and cobalt segregation at dislocations on nickel-based superalloys. Scr. Mater. 2018, 145, 76-80. [CrossRef]

42. Mianroodi, J.; Shantraj, P.; Kontis, P.; Cormier, J.; Gault, B.; Svendsen, B.; Raabe, D. Atomistic phase field chemomechanical modeling of dislocation-solute-precipitate interaction in Ni-Al-Co. Acta Mater. 2019, 175, 250-261. [CrossRef]

43. Jouiad, M.; Marin, E.; Devarapalli, R.; Cormier, J.; Ravaux, F.; Le Gall, C.; Franchet, J.M. Microstructure and mechanical properties evolutions of alloy 718 during isothermal and thermal cycling over-aging. Mater. Des. 2016, 102, 284-296. [CrossRef]

44. Legros, M.; Dehm, G.; Arzt, E.; Balk, T. Observation of giant diffusivity along dislocation cores. Science 2008, 319, 1646-1649. [CrossRef]

45. Skrotzki, B.; Shiflet, G.; Starke, E. On the effect of stress on nucleation and growth of precipitates in an Al-Cu-Mg-Ag Alloy. Mater. Trans. A 1996, 27A, 3431-3443. [CrossRef]

46. Sauthoff, G. Long-range ordering in the early stages of precipitation-A brief review. Metall. Mater. Trans. A 1994, 25, 2565-2568.

47. Cormier, J.; Milhet, X.; Mendez, J. Non-isothermal creep at very high temperature of the nickel-based single crystal superalloy MC2. Acta Mater. 2007, 55, 6250-6259. [CrossRef]

48. Véron, A.; Bréchet, Y.; Louchet, F. Strain induced directional coarsening in ni based superalloys. Scr. Mater. 1996, 34, 1883-1886. [CrossRef]

49. Caccuri, V.; Cormier, J.; Desmorat, R. $\gamma^{\prime}$-rafting mechanisms under complex mechanical stress state in Ni-based single crystalline superalloys. Mater. Des. 2017, 131, 487-497. [CrossRef]

50. Pineau, A. Influence of uniaxial stress on the morphology of coherent precipitates during coarsening-Elastic energy considerations. Acta Meter. 1976, 24, 559-564. [CrossRef]

51. Reed, R.; Matan, N.; Cox, D.; Rist, M.; Rae, C. Creep of CMSX-4 superalloy single crystals: Effects of rafting at high temperature. Acta Mater. 1999, 47, 3367-3381. [CrossRef]

52. Svetlov, I.; Golovko, B.; Epishin, A.; Abalakin, N. Diffusional mechanism of $\gamma^{\prime}$-phase particles coalescence in single crystals of nickel-base superalloys. Scr. Mater. 1992, 26, 1353-1358. [CrossRef]

53. Tien, J.; Copley, S. The effect of orientation and sense of applied uniaxial stress on the morphology of coherent gamma prime precipitates in stress annealed nickel-base superalloy crystals. Meter. Trans. 1971, 2, 543-553. [CrossRef]

54. Tien, J.; Gamble, R. Effects of stress coarsening on coherent particle strengthening. Meter. Trans. 1971, 3, 2157-2162. [CrossRef]

55. Cao, L.; Wollgramm, P.; Bürger, D.; Kostka, A.; Cailletaud, G.; Eggeler, G. How evolving multiaxial stress states affect the kinetics of rafting during creep of single crystal Ni-base superalloys. Acta Mater. 2018, 158, 381-392. [CrossRef]

56. Ha, J.; Seong, J.; Jeong, J.; Choi, Y.; Kang, N. Effects of the aging temperature and stress relaxation conditions on $\gamma^{\prime}$ precipitation in Inconel X-750. J. Nucl. Mater. 2015, 457, 362-368. [CrossRef] 
57. Farvizi, M.; Asgari, S. Effects of cold work prior to aging on microstructure of AEREX'M350 superalloy. Mater. Sci. Eng. A 2008, 480, 434-438. [CrossRef]

58. Tien, J.; Gamble, J. The influence of applied stress and stress sense on grain boundary precipitate morphology in a nickel-base superalloy during creep. Meter. Trans. 1971, 2, 1663-1667.

59. Schulz, F.; Li, H.; Kitaguchi, H.; Child, D.; Williams, S.; Bowen, P. Influence of Tertiary Gamma Prime $\left(\gamma^{\prime}\right)$ Size Evolution on Dwell Fatigue Crack Growth Behavior in CG RR1000. Mater. Trans. A 2018, 49A, 3874-3884. [CrossRef]

60. Frenz, H.; Kinder, J.; Klingelhöffer, H.; Portella, P. Behavior of single crystal superalloys under cycling loading at high temperatures. In Proceedings of the International Symposium on Superalloys, Seven Springs, PA, USA, 22-26 September 1996; pp. 305-312.

61. Vengrenovitch, R. On the ostwald ripening theory. Acta Meter. 1982, 30, 1079-1086. [CrossRef]

62. Durand, M. Analyse Des Mécanismes Métallurgiques Survenant Dans L'alliage AD730TM Au Cours De Revenu De Relaxation Des Contraintes. Ph.D. Thesis, Ecole Nationale des Mines de Paris-CEMEF, Paris, France. in progress.

63. Girifalco, L.; Grimes, H. The Theory of Diffusion on Strained Systems; US Government Printing Office: Washington, DC, USA, 1958.

64. Forestieri, A.; Girifalco, L. The effect of plastic deformation on self-diffusion in silver. J. Phys. Chem. Solids 1959, 10, 99-105. [CrossRef]

65. Kubicek, M.; Cai, Z.; Ma, W.; Yildiz, B.; Hutter, H.; Fleig, J. Tensile lattice strain accelerates oxygen surface exchange and diffusion in La1-xSrxCoO3-delta thin films. ACS 2013, 7, 3276-3286.

66. Angiolini, M.; Mazzone, G.; Montone, A.; Vittori-Antisari, M. Effect of plastic deformation on the kinetics of the solid state reaction between $\mathrm{Cu}$ and Zn. Phys. Rev. B 1999, 59, 11733-11738. [CrossRef]

67. Nechaev, Y.; Vladimirov, S.; Olshevskii, N.; Khlomov, V. On the effect of high-rate strain on diffusion mass transfer in metals. Phys. Stat. Solidi 1986, 553-560. [CrossRef]

68. Johnson, W. Precipitate shape evolution under applied stress-Thermodynamics and kinetics. Meter. Trans. A 1987, 18A, 233-247. [CrossRef]

69. Ola, O.T.; Ojo, O.A.; Wanjara, P.; Chaturvedi, M.D. Analysis of microstructural changes induced by linear friction welding in a nickel-based superalloy. Metall. Mater. Trans. A 2011, 42A, 3761-3777. [CrossRef]

70. Prikhodko, S.; Ardell, A. Coarsening of $\gamma^{\prime}$ in Ni-Al alloys aged under uniaxial compression: I. Early-stage kinetics. Acta Mater. 2003, 51, 5001-5012. [CrossRef]

(C) 2020 by the authors. Licensee MDPI, Basel, Switzerland. This article is an open access article distributed under the terms and conditions of the Creative Commons Attribution (CC BY) license (http://creativecommons.org/licenses/by/4.0/). 